\title{
Increase of island endemism with altitude - speciation processes on oceanic islands
}

\author{
Manuel Jonas Steinbauer, Rüdiger Otto, Agustín Naranjo-Cigala, Carl Beierkuhnlein \\ and José-María Fernández-Palacios
}

M. J. Steinbauer (manuel.steinbauer@uni-bayreuth.de) and C. Beierkuhnlein, Lehrstuhl Biogeografie, Univ. Bayreuth, DE-95447 Bayreuth, Germany. - R. Otto and J.-M. Fernández-Palacios, Depto de Ecología, Facultad de Biología, Univ. de La Laguna, ES-38206 La Laguna, Tenerife, Islas Canarias, Spain. - A. N. Cigala, Depto de Geografia, Univ. de Las Palmas de Gran Canaria, ES-35003 Las Palmas de Gran Canaria Islas Canarias, Spain.

\begin{abstract}
Understanding speciation on oceanic islands is a major topic in current research on island biogeography. Within this context, it is not an easy task to differentiate between the influence of elevation as an indicator for habitat diversity and island age as an indicator for the time available for diversification. One reason for this is that erosion processes reduce the elevation of islands over time. In addition, the geographic distance to source ecosystems might differ among habitats, which could lead to habitat-specific reduction of species immigration, niche occupation and diversification. We used the percentage of single island endemic species (pSIE) in five different zonal ecosystems (distributed in altitude) on the Canary Islands as an indicator for diversification. We tested whether diversification increases with altitude due to a greater ecological isolation of high elevation ecosystems on oceanic islands under the assumption of a low elevation source region on the mainland. In addition we tested whether the 'hump-shaped' (unimodal) relationship between pSIE and island age as well as the linear relationship between species richness and pSIE is consistent across spatial scales. We also analyse a potential influence of island area and habitat area. We found that pSIE increases with elevation. The relations between species richness as well as age with pSIE are consistent across scales. We conclude that high elevation ecosystems are ecologically isolated. Surprisingly, the altitudinal belt with the strongest human influences has the highest values of pSIE. We successfully transfer the 'general dynamic theory of island biogeography' to the ecosystem scale, which provides multiple opportunities for future studies. With this approach we find that the effects of elevation on diversification can be separated from those of island age.
\end{abstract}

Species distribution on island archipelagos depends on immigration, extinction and speciation. Separating the effects and interactions of these processes is not an easy task. Recently, the importance of diversification on islands has been particularly emphasised. Emerson and Kolm (2005a) suggest using the percentage of single-island endemics (pSIE) as an indicator for diversification on island archipelagos. Working with data on arthropods and seed plants for both the Canary and Hawaii Islands they found pSIE to be strongly correlated with species richness. They propose that species richness promotes speciation due to intensified interspecific competition leading to extinction and genetic adaptation. This 'diversitydriven speciation' hypothesis has been discussed by various authors (Cadena et al. 2005, Kiflawi et al. 2007, Pereira et al. 2007, Whittaker et al. 2007, Witt and Maliakal-Witt 2007, Birand and Howard 2008, Gruner et al. 2008, Vilenkin et al. 2009). Cadena et al. (2005) argue that both species richness as well as endemism is influenced by island age leading to a fortuitous correlation of the variables. This is the case, as on the one hand endemic species will accumulate on an island over time and local populations differentiate while populations on other islands become extinct. On the other hand the species number will always increase with island age through colonisation as long as extinction rates are relatively low. However, the latter statement is only valid for islands where equilibrium has not been reached (Emerson and Kolm 2005b).

In their 'island immaturity speciation pulse model' Whittaker et al. (2007) suggested island age as a key parameter determining species distribution and endemism. They postulated a concept of island evolution that starts with an early island stage in which an island reaches maximum area and altitude through volcanic activity over an erosion-driven topographically and geologically heterogeneous development to a flat, topographically simple island that ultimately disappears beneath the sea's surface. In their theoretical model, speciation is driven by the availability of non-occupied ecological niches and is highest at a stage in the island's development with time when the species number has not yet reached its carrying capacity. The model was further refined by Whittaker et al. $(2008,2010)$. According to the model of Whittaker et al. (2007, 2008, 2010), pSIE follows an idealised hump-shaped 
curve following the ontogeny of an island: at the beginning, when species are immigrating from nearby islands, no SIE will be present on the newly formed island. Due to the limited number of species, the availability of ecological niches is high and the speciation rate (and simultaneously pSIE) will also increase. With the island becoming older a development stage is reached whereby more species will become extinct than those newly established on the island (either due to speciation or immigration). According to Whittaker et al. (2008) not only the species number and the number of SIE but also the pSIE will decline. Several reasons are mentioned: firstly, SIE may colonise newly established islands within the archipelago and thus lose their status as SIE. Secondly, it is said that multi-island endemics and non-endemic species are viable in smaller population sizes due to a possible immigration from other islands (Triantis et al. 2008). Thus, SIE are more likely to go extinct with the decline in suitable habitat due to a decline in island area. Thirdly, an increase in habitat similarity within the island and with neighbouring islands due to a flattening of the island will result in a decrease in speciation of neo-endemic habitat specialists, while coastal generalists will persist. In general this assumption would also predict low pSIE for coastal ecosystems.

Several authors have discussed whether or not null models could describe the investigated link between pSIE and species richness for both the Canary Islands (Emerson and Kolm 2007, Kiflawi et al. 2007, Witt and Maliakal-Witt 2007, Birand and Howard 2008) and Hawaii (Gruner et al. 2008). The question is whether the apparent positive correlation between total species number and the percentage of endemics is coincidental or not. Vilenkin et al. (2009) argue that the observed patterns might be the by-product of an exponential relationship between the numbers of cooccurring endemic and non-endemic species caused by narrower ranges of endemic species compared to co-occurring non-endemic species. Pereira et al. (2007) point out that species richness and pSIE are correlated with various physical variables such as island size and elevation. It is therefore likely that the correlation between species richness and pSIE reflects a dependency on different variables or, more likely, on the same variable but through different mechanisms that have not yet been detected.

In this paper we suggest mechanisms that could describe the correlation of species richness and pSIE based on general island biogeography processes. We test the hypothesis that species distribution depends on the availability of niche space with speciation being additionally driven by isolation and that both the availability of niche space and isolation are, for the Canary Islands, dependent on elevation (hypothesis 1). In addition we investigate whether patterns for pSIE and species richness are consistent across scales and therefore could be identified when comparing ecosystems of these islands instead of complete islands (hypothesis 2).

\section{Theory of island biogeography}

One of the paradigms of the equilibrium theory of island biogeography as proposed by MacArthur and Wilson (1967) is that the immigration of species depends mainly on the distance to potential source regions, while the extinction rate depends on the size of the island. Brown and Kodric-Brown (1977) incorporated the 'rescue effect' stating that extinction is also influenced by distance, whereas Lomolino (1990) highlighted that immigration is also influenced by island area ('target effect'). Later, Heaney (2000) and Lomolino (2000) came up with two theoretical models relating immigration, extinction and speciation. Both argue that with increased isolation, the immigration rate declines, while the speciation rate increases due to genetic isolation and unoccupied ecological niche space.

\section{The Canary Islands}

On the Canary Islands we encounter a unique situation compared to other oceanic archipelagos. Although there is some evidence for colonization from other Macaronesian archipelagos through the Iberian Peninsula (Marshall and Baker 1999, Fernández-Palacios et al. 2011) it is realistic to assume that the north-western part of the African mainland has been an important source region for the Canarian biota; Fuerteventura is currently $95 \mathrm{~km}$ from the African coast, and was only $60 \mathrm{~km}$ apart during the last Glaciation, just $18 \mathrm{Ky} \mathrm{ago} \mathrm{(García-}$ Talavera 1999). North Africa has been subjected to a progressive climatic deterioration over time, especially after the occurrence of several geological events in the Neogene. Among them are the closure of the corridor between the Indian and Atlantic Oceans, the closure of the Gibraltar strait leading to the Messinian salinity crisis, the arrival of Glaciation cycles and the onset of the Mediterranean climate in the Pleistocene bringing several desertification cycles to the Saharan region (Stanley 1999). These historic environmental conditions on the African continent might be more important for plant species diversity on the Canary Islands than present conditions, as many species might have migrated from the nearby continent in the past. Such importance of historic conditions for variation in plant species diversity on the Canary islands was also shown by Zobel et al. (2011) who find plant species diversity on the Canary islands to be strongly related to historic (pre human) habitat area and island age.

As the Moroccan-Saharan coastal plains are lowlands, immigrating species from this origin are adapted to low elevation ecosystems and will therefore occupy habitats and ecosystems in the low altitudes of the islands. The elevation on Gran Canaria, Tenerife, La Palma and El Hierro exceeds the Moroccan-Saharan coastal plains by far. Comparable elevations to the Pico de Teide $(3718 \mathrm{~m})$ only occur in the High Atlas Mountains of Morocco (Djebel Toubkal, 4167 $\mathrm{m})$ at a distance of ca $900 \mathrm{~km}$. This substantially exceeds the distance from coast to coast. Thus, the distance from island ecosystems to ecosystems of similar environmental conditions increases with elevation (Fig. 1a). As dispersal is dependent on distance, habitats placed at higher elevations on the islands are geographically more isolated from ecosystems of similar environmental conditions. Even if an equal number of diaspores or individuals of continental species may arrive in all elevation zones, most of them will very likely originate from geographically closer regions. As these diaspores would come from a low elevation ecosystem on the continent, most of those species will not be able to establish in high elevation ecosystems due to 


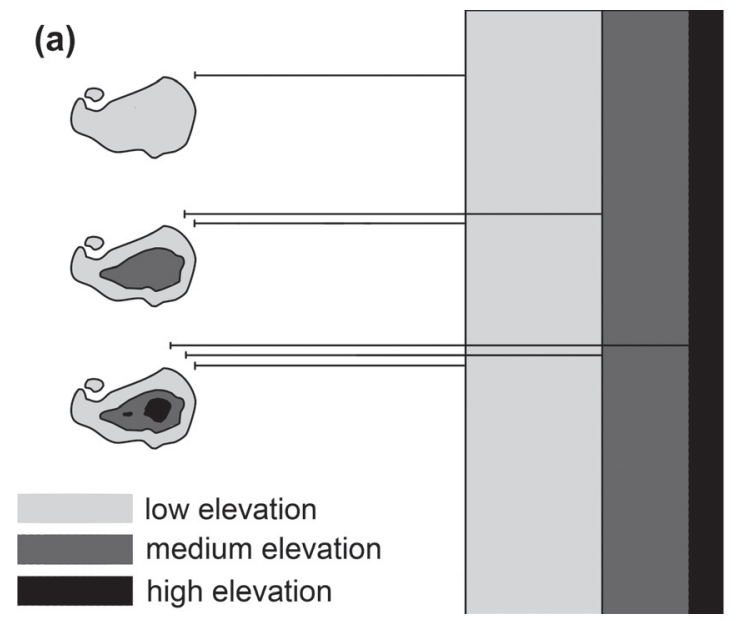

(b)

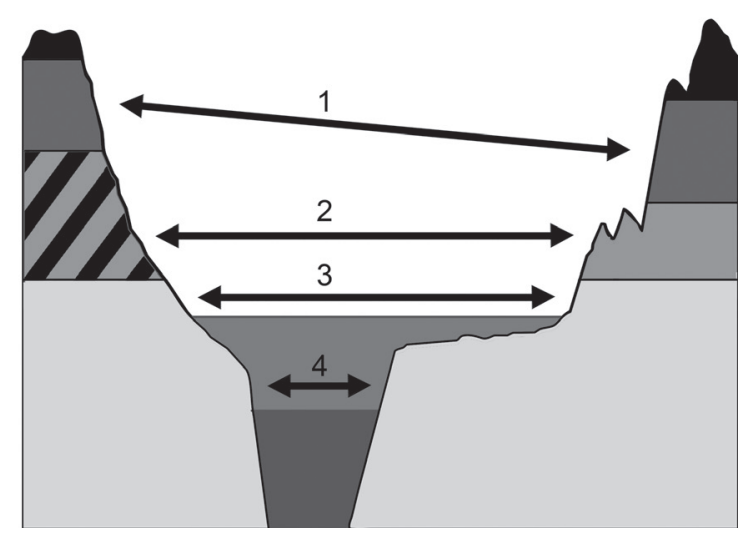

Figure 1. Theoretical relationship between elevation and isolation on oceanic islands. (a) Isolation can be caused by elevation, as different geographical distances from the ecosystem on an island (left side) to its source region on the mainland (right side) have to be taken into consideration when ascertaining the distance a species has to cross to reach a suitable habitat on an island. If immigrating species are mainly adapted to low elevation ecosystems according to the altitudes of their nearby source region, they will leave habitats in high elevations unoccupied. This situation promotes in situ speciation in the high altitude ecosystems leading to a high percentage of endemic species. (b) However, when comparing islands (left side) with the mainland (right side), ecosystems are not necessarily associated with the same elevation range due to several reasons: 1) ecosystems might be situated at different elevation levels, due to a change in temperature gradients; 2) ecosystems of the same band might contain completely different species, due to changes in climatic or edaphic conditions; 3 ) although occasionally it can be assumed that these are similar across altitudes; and finally, 4) due to Pleistocene' sea surface fluctuations, neither elevation nor distance can be treated as being constant in time.

unsuitable environmental conditions. It has already been shown that directional ecological filtering is very important for the colonization of non-native species into high altitude regions worldwide, and this mechanism might be also working for native species (Alexander et al. 2011). Even though one has to be careful when comparing island and continental ecosystems (Fig. 1b), the described mechanism results in a situation where many species occupy low elevations while the niche space available at higher elevations remains empty. This combination provides optimal conditions for diversification at the higher altitudes.

Given the importance of both, available niche space and isolation for diversification rates, we can formulate two hypotheses.

H1. If speciation is driven by the availability of unoccupied niche space and enabled by isolation, it should increase with island elevation. pSIE, as an indicator for overall diversification, should follow this tendency. Both Emerson and Kolm (2007) and Pereira et al. (2007) agreed in that the identified correlation between species richness and the pSIE could be due to the influence of one variable driving both distribution patterns through different mechanisms. This variable might be island altitude; on the Canary Islands, elevation is correlated with environmental variations and thus habitat diversity (Steinbauer and Beierkuhnlein 2010), which in turn is correlated with island size. In addition to this, as mentioned before, high elevations form isolated areas where speciation may take place. However, if the species exchange between the islands of an archipelago is relatively high, it is likely that species evolving on one island also colonize another one, or that species do not evolve on one, but on several islands. In these cases the proportion of multi-island endemic species (i.e. species endemic to the archipelago) should increase with elevation.
H2. Processes and linkages identified by comparing islands within one archipelago should also be observable when comparing specific ecosystems that are present on these islands. This implies that for the different altitudinal ecosystems both the positive correlation between species richness and pSIE identified by Emerson and Kolm (2005b) and the hump-shaped relationship between island age and pSIE identified by Whittaker et al. (2007) should also be detected for inter-ecosystem relationships.

\section{Methods}

Canarian native seed plants (Spermatophyta) were assigned to the five major zonal ecosystems of the archipelago based on the literature (Izquierdo et al. 2004) and personal experience. 'Potentially native species' were excluded to prevent errors. Altogether 932 species were included in the analysis. The distribution of main ecosystems on the Canary Islands follows an altitudinal gradient (see detailed description in Zobel et al. 2011). Roughly $60 \%$ of the species were assigned to one zonal ecosystem (including the main representatives of the different altitudinal ecosystems such as Euphorbia canariensis (subdesert coastal scrub), Juniperus turbinata (thermophilous woodlands), Laurus novocanariensis (laurel forest), Pinus canariensis (pine forest) or Spartocytisus supranubius (subalpine scrub)), whereas ca $40 \%$ of the species were found to have a larger altitudinal distribution, occurring in two to five zonal ecosystems depending on their ecological amplitude. Species occurring in more than one zonal ecosystem were therefore assigned to each ecosystem where they occur. This poses the problem of pseudoreplication, which we can only partly control for by including island as random effect in some of the calculations (see below). Analyses 
Table 1. a) Proportion of single island endemics, b) proportion of multi-island endemic species (MIEs), c) number of native species and d) habitat area (in $\mathrm{km}^{2}$; rounded off), listed for specific ecosystems and islands. Those values that were not included in the calculation are in grey. H: El Hierro, P: La Palma, G: La Gomera, T: Tenerife, C: Gran Canaria, F: Fuerteventura, L: Lanzarote.

\begin{tabular}{|c|c|c|c|c|c|c|c|c|}
\hline & $\mathrm{H}$ & $P$ & G & $\mathrm{T}$ & $\mathrm{C}$ & $\mathrm{F}$ & L & Total \\
\hline \multicolumn{9}{|l|}{ a) } \\
\hline Coastal scrub & 4.0 & 4.2 & 5.9 & 15.9 & 7.7 & 2.6 & 3.8 & 24.5 \\
\hline Thermophilous woodland & 6.8 & 7.1 & 12.6 & 18.1 & 15.7 & 3.3 & 3.6 & 36.7 \\
\hline Laurel forest & 2.8 & 8.4 & 5.3 & 8.8 & 6.7 & - & - & 21.9 \\
\hline Pine forest & 1.8 & 13.2 & - & 10.9 & 24.8 & - & - & 34.4 \\
\hline $\begin{array}{l}\text { Subalpine scrub } \\
\text { b) }\end{array}$ & - & 9.5 & - & 24.4 & - & - & - & 29.2 \\
\hline Coastal scrub & 27.8 & 29.8 & 30.9 & 26.6 & 23.9 & 19.8 & 19.5 & 23.7 \\
\hline Thermophilous woodland & 28.6 & 31.8 & 30.2 & 31.5 & 25.3 & 21.2 & 19.0 & 26.1 \\
\hline Laurel forest & 26.4 & 26.6 & 29.4 & 26.9 & 24.0 & 12.0 & 8.5 & 24.8 \\
\hline Pine forest & 27.3 & 25.0 & 25.0 & 26.3 & 18.0 & 11.1 & 7.7 & 20.5 \\
\hline $\begin{array}{l}\text { Subalpine scrub } \\
\text { c) }\end{array}$ & 21.2 & 34.9 & 14.3 & 31.7 & 27.9 & 4.1 & 4.0 & 29.2 \\
\hline Coastal scrub & 176 & 191 & 220 & 327 & 285 & 268 & 262 & 485 \\
\hline Thermophilous forest & 147 & 154 & 182 & 238 & 198 & 151 & 137 & 349 \\
\hline Laurel forest & 178 & 203 & 228 & 249 & 208 & 92 & 82 & 319 \\
\hline Pine forest & 110 & 136 & 112 & 156 & 161 & 63 & 65 & 224 \\
\hline Subalpine scrub & 33 & 63 & 35 & 82 & 43 & 24 & 25 & 89 \\
\hline $\begin{array}{l}\text { Total } \\
\text { d) }\end{array}$ & 340 & 415 & 432 & 626 & 533 & 345 & 323 & 932 \\
\hline Coastal scrub & 81 & 64 & 122 & 607 & 852 & 1626 & 824 & 4177 \\
\hline Thermophilous forest & 69 & 153 & 137 & 359 & 203 & 27 & 18 & 967 \\
\hline Laurel forest & 66 & 189 & 103 & 412 & 193 & 0 & 0 & 962 \\
\hline Pine forest & 52 & 285 & 6 & 441 & 309 & 0 & 0 & 1092 \\
\hline Subalpine scrub & 0 & 15 & 0 & 213 & 0 & 0 & 0 & 228 \\
\hline Total & 268 & 707 & 368 & 2033 & 1558 & 1657 & 845 & 7436 \\
\hline
\end{tabular}

were restricted to those zonal ecosystems that actually occur on an island $(\mathrm{n}=25$ and not $5 \times 7=35)$. For instance, on Fuerteventura and Lanzarote, laurel forest, pine forest and subalpine scrub were not considered, as they do not exist on these islands. The percentages of singe-island endemics (pSIE) and multi-island endemics (pMIE; species endemic to the archipelago) were calculated for all zonal ecosystems on all islands (Table 1).

The potential (Holocene) altitudinal ranges for the ecosystems (Table 2) are not the same for the island's windward and leeward slopes and may vary among islands. While e.g. the pine forest extends around the islands, the laurel forest is limited to the islands windward slopes. Above the tree line of the pine forest we cannot find any distinction between the windward and leeward sides in the subalpine zone. Based on this, we considered the lowest limits of the ecosystems along the windward slope for the calculations, as all the zonal ecosystems are represented there (Table 2). The area covered by the elevation belts was estimated using the potential distribution of natural vegetation (del Arco Aguilar 2006, Table 1d), assigning all vegetation types to the five major habitats defined for our study.

Table 2. Potential altitudinal ranges (in $\mathrm{m}$ ) of the ecosystems as approximated for the Holocene. The lowest limits from the windward island side were considered for the linear correlation.

\begin{tabular}{lcc}
\hline & Windward & Leeward \\
\hline Coastal scrub & $0-300$ & $0-400$ \\
Thermophilous woodland & $300-600$ & $400-700$ \\
Laurel forest & $600-1200$ & - \\
Pine forest & $1300-2000$ & $700-2300$ \\
Subalpine scrub & $2000-3000$ & \\
\hline
\end{tabular}

The increase of pSIE with elevation was tested using generalized linear mixed models with a binomial family error, testing for island as a random effect. The linear relation with elevation was also tested for pMIE. To assess the influence of area, additional models including island and habitat area (quadratic-, log-and untransformed) were compared to the afore-mentioned simpler models.

The postulated linear relationship between pSIE and species richness at the ecosystem scale was also evaluated using generalized linear mixed models with a binomial family error, testing for island or habitat or both as random effects, respectively. Island and habitat area (quadratic-, log- and untransformed) were additionally tested for influence. In a separate model, elevation and its interaction with species richness was included in the model with island as random effect.

To test whether the hump-shaped (unimodal) link of pSIE with age as reported for the inter-island scale (Whittaker et al. 2007, 2008) can also be identified for the inter-ecosystem scale, we compared two alternative generalized linear mixed models with a binomial family error testing for habitat as a random effect with and without age ${ }^{2}$ as an additional predictor. As these ecosystems occur at similar elevations on all islands, altitude does not influence a possible relationship between pSIE and island age here. Again, the hypothesis was also assessed for pMIE. In addition, we tested the influence of island and habitat area (quadratic-, log- and untransformed) and included elevation and its interaction with the other predictors in those models with island as random effect. To refine the influence of habitat area on pSIE as well as pMIE, we tested models combing age and age $^{2}$ with log-habitat area and log-habitat area ${ }^{2}$ with habitat as random effect. 
All calculations were performed using the statistical program R (R Development Core Team 2010). We used package 'Ime4' ver. 0.999375-32 (Bates and Maechler 2009) for the generalised linear mixed effect models. Models were fitted using maximum likelihood, to enable a comparison between models with different fixed effects. Models were compared using ANOVA. See Bunnefeld and Phillimore (2011) for a discussion on the use of linear mixed models in island biogeography.

To visually assess possible differences in the relationship between island age and overall diversification between altitudinal zones, we plotted pSIE against island age for coastal scrub and thermophilous woodland ecosystems. We compared the resulting plots with the plots on the relationship between pSIE for the whole island and island age presented by Whittaker et al. (2007). These results were reproduced using data obtained from Izquierdo et al. (2004).

Following Whittaker et al. (2007), island age addresses the time span that has been available for immigration and diversification processes, which in most cases corresponds to the geological age. These authors suggest an age of 3.5 Myr for Gran Canaria assuming a volcanic eruption that sterilised the island (Marrero and Francisco-Ortega 2001). This assumption is criticized by Anderson et al. (2009) who propose an age of $14.5 \mathrm{Myr}$. We evaluate both hypotheses in our models. For Tenerife an age of $8 \mathrm{Myr}$ was assumed, corresponding to the emersion of the three basaltic massifs that today form Tenerife's edges (Anguita et al. 2002).

\section{Results}

A significant $(p=0.001)$ increase of $p S I E$ with elevation was identified by the generalized linear mixed model with island as a random effect (Fig. 2a; slope: $0.0003 \pm 0.0001$; increase of pSIE $\sim 0.01-0.04 \mathrm{~km}^{-1}$ ) (overview of model results in Table 3; slopes are always reported for binomial model with a logit link). There was no significant relationship between pMIE with elevation, species richness, habitat area or island area.

Both pSIE and species richness were found to be related on the ecosystem scale. Interestingly, we identified a positive relationship with habitat as random effect $(\mathrm{p}<0.001$; Fig. $2 \mathrm{c}$; slope: $0.0133 \pm 0.0015)$ but a negative relationship with islands as random effect $(\mathrm{p}<0.01$; Fig. 2b; slope: $-0.0029 \pm 0.0009)$. A positive relation was identified having both as random effects $(p=0.03$; slope: $0.0071 \pm 0.0023$ ). Random effect variance estimates (intercept) are $0.2252 \pm 0.4745$ for island and $0.6808 \pm 0.8251$ for habitat, respectively. Including a term for the habitat area (quadratic- and untransformed) in the model with the habitat as random effect significantly increased model performance but did not affect the significance of species richness. The interaction of elevation and species richness was non significant.

We found evidence for the hump-shaped (unimodal) relationship between pSIE and island age (time available for speciation) postulated by Whittaker et al. $(2007,2008)$ (Fig. $2 d)$. Model performance increased significantly $(p<0.001)$ when age $^{2}$ was included in the generalized linear mixed model with habitat as a random effect. The model parameter for age $^{2}$ is negative, resulting in the 'humped' shape (slope age: $0.2435 \pm 0.0354$, slope age ${ }^{2}:-0.0154 \pm 0.0021$ ). We identified a significant interaction of elevation with age $^{* * *}$ and age $^{2 *}$. Area significantly increased model performance (log-habitat area $\mathrm{p}<0.001$; island area $\mathrm{p}<0.01$, $\log$-island area $\mathrm{p}<0.001$, island $\operatorname{area}^{2} \mathrm{p}<0.05$ ) but did not question the significance of age or age ${ }^{2}$. When habitat was treated as a random effect, log habitat area and log habitat area $^{2}$ were found to be significant predictors of pSIE (slope $\log$ habitat area: $3.0818 \pm 0.5448$, slope $\log$ habitat area ${ }^{2}$ : $-0.2619 \pm 0.0512)$, rendering a hump shaped relationship (Fig. 2e). When coastal scrub was excluded from the analyses, the model supported a linear relation with pSIE, leaving loghabitat area ${ }^{2}$ non-significant. A combined model of log habitat area*, $\log$ habitat area ${ }^{2 *}$, age ${ }^{* * *}$ and age $^{2 * * *}$ for all zonal ecosystems revealed all four predictors to be significant.

The relationship between pMIE and age was also 'hump-shaped' as indicated by a significantly $(\mathrm{p}<0.01)$ increased model performance after including age ${ }^{2}$ (slope age: $0.0385 \pm 0.0201$, slope age $\left.{ }^{2}:-0.0029 \pm 0.0010\right)$. Model performance was additionally enhanced after including habitat area or island area (Table 3). Log habitat area and log habitat area ${ }^{2}$ significantly explained pMIE (slope log ha area: $0.6888 \pm 0.2331$, slope log ha area ${ }^{2}:-0.0722 \pm 0.0222$ ) when habitat was a random effect. Significance of log habitat area and log habitat area ${ }^{2}$ was lost after including age* and age $^{2 * *}$ as additional predictors.

Assuming an age of 14.5 Myr (instead of 3.5 Myr) for Gran Canaria, the hump-shaped (i.e. unimodal) relationships with age of pSIE and pMIE remained significant (not shown in Table 3). These results can be clearly seen in Fig. 3a where for the ecosystems of 'coastal scrub' and 'thermophilous forest' pSIE follows a hump-shaped relationship with island age, consistent with the findings of Whittaker et al. (2007) on an island scale (Fig. 3b). The smaller ratios for pSIE in Fig. $2 b$ compared to Fig. 3a result from the overall smaller number of species within our data set that is ecosystem-specific for Spermatophyta compared to the one provided by Izquierdo et al. (2004).

We also identified a surprisingly high percentage of SIE in the 'thermophilous forest' that is consistent for most islands of the Canarian archipelago except for La Palma and Lanzarote (Table 1a). The same pattern emerged with different ratios when looking at the pMIE (Table 1b). Here, even La Palma had a second maximum in the ecosystem of the 'thermophilous forest'. Overall, species numbers decline with elevation (Table 1c).

\section{Discussion}

The existence of a general increase of pSIE with altitude (our hypothesis 1) is supported by our results, which indicate increasing diversification rates with elevation. We suggest that species inhabiting high altitude ecosystems on islands are genetically more isolated than their low elevation counterparts due to a larger spatial distance to comparable ecosystems (and thus lower immigration rates of potential colonizers many diaspores of species that are not able to establish viable populations in high elevations may still arrive). This is supported by Zobel et al. (2011), who found the number of ancient immigrants in high elevation ecosystems on the 
(a)
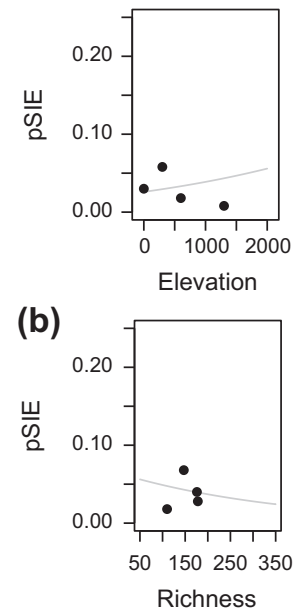

(c)
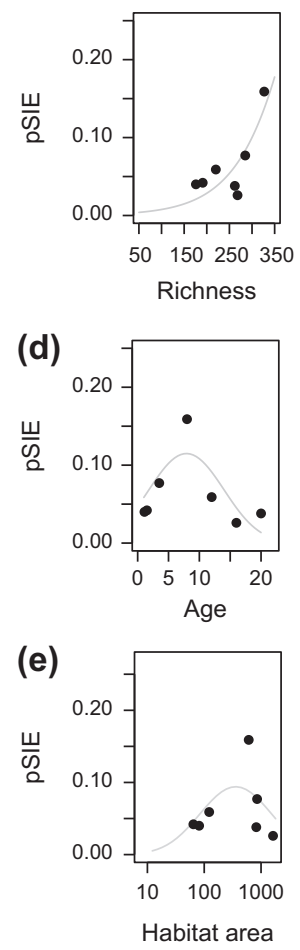
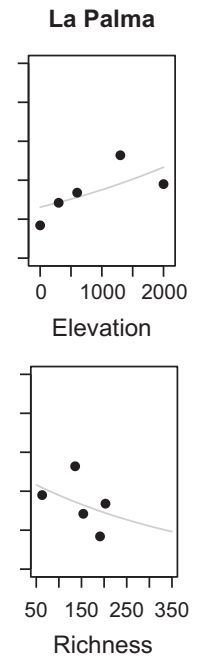
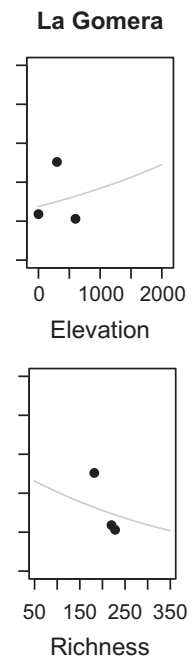
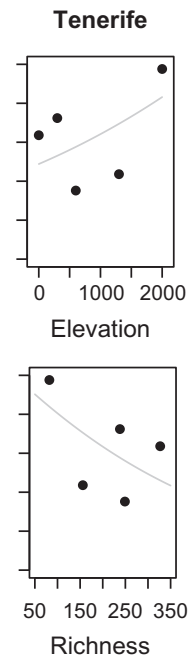

Pine forest

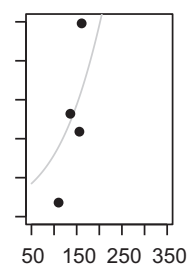

Richness
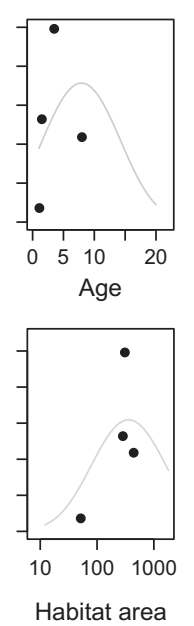

Gran Canaria
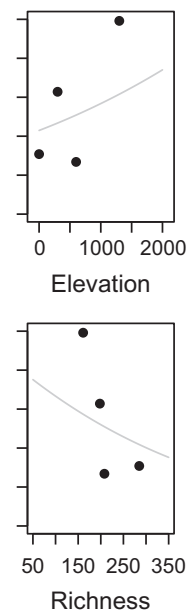
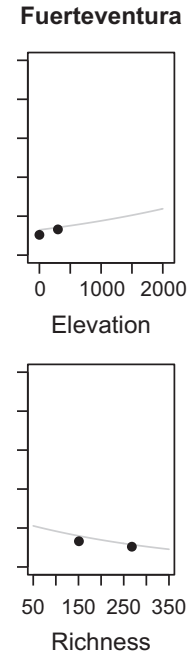

Lanzarote
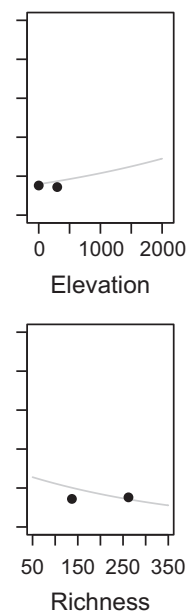

Summit scrub

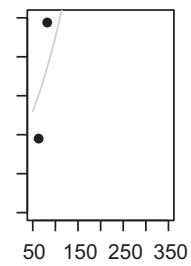

Richness
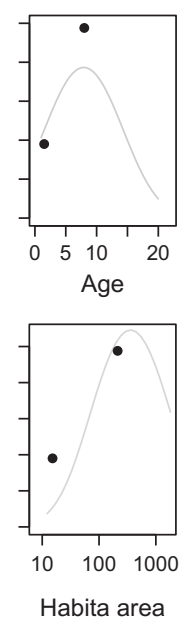

Figure 2. Observed relationships between the percentage of Single Island Endemics and elevation. (a) The increase of pSIE with elevation could indicate an increase of speciation. (b) A decline of pSIE with species richness within islands can be seen as a logical result. However, within ecosystems on different islands both (c) a positive relation between species richness and pSIE and (d) a hump shaped relation between pSIE and age are observed. This is consisted with island scale analyses (comparing entire islands): (e) the relation of (log-)habitat area with pSIE is also hump shaped, but becomes linear if coastal scrub is removed from the analysis (not shown). The grey line indicates model predictions as derived from general mixed effect models integrating either all islands or habitats, in one analysis.

Canary Islands to be smaller than expected from habitat area and island age. In situ speciation caused by the availability of ecological niches within the isolated high elevation ecosystems is, however, only one among other influential factors for SIE on island archipelagos. The heterogeneity within the data indicates that other factors such as the temporal availability and the spatial extent of ecosystems, the disturbance regimes, the geological evolution of specific islands [with sterilization (Gran Canaria), coalescence (Tenerife) or fragmentation (Lanzarote-Fuerteventura) events] and, last but not least, the properties of the specific species will all majorly contribute to species distribution on these island systems. In addition, Whittaker et al. $(2007,2008,2010)$ highlight the importance for directed intra-island species colonisation from older islands to the new, recently emerged, one. This process includes already submerged islands and can thus be much older than the present archipelago (Fernández-Palacios et al. 2011). Steinbauer and Beierkuhnlein (2010) found strong indication that for the Canary Islands within-island species exchange is more important than external immigration, although the latter 
Table 3. a) Model performance of the generalized linear mixed models with binomial family errors. Note that the model did not use percentage values as dependent variables but binomial proportions (SIE, n.spec-SIE). b) Smaller AIC values after including area as an additional predictor indicate better model performance. Significance of the additional predictor (area) is indicated with the AIC values $\left(p<0.05^{*}\right.$, $\left.\mathrm{p}<0.01^{* *}, \mathrm{p}<0.001^{* * *}\right)$. Note that including area into the model never questioned the significance of the original predictor(s).

a) original model

b) original model + additional predictor

\begin{tabular}{|c|c|c|c|c|c|c|c|c|c|c|}
\hline dependent & predictors & random & $\begin{array}{c}\text { model } \\
\text { p-value }\end{array}$ & $\begin{array}{l}\text { AIC } \\
\text { model }\end{array}$ & $\begin{array}{l}\mathrm{AIC}+ \\
\text { habitat } \\
\text { area }\end{array}$ & $\begin{array}{c}\mathrm{AIC}+ \\
\log \\
\text { (habitat area) }\end{array}$ & $\begin{array}{l}\text { AIC + } \\
\text { habitat } \\
\text { area }^{2}\end{array}$ & $\begin{array}{l}\mathrm{AIC}+ \\
\text { island } \\
\text { area }\end{array}$ & $\begin{array}{c}\mathrm{AIC}+ \\
\log \\
\text { (island area) }\end{array}$ & $\begin{array}{l}\mathrm{AIC}+ \\
\text { island } \\
\text { area }^{2}\end{array}$ \\
\hline $\mathrm{pSIE}^{1}$ & $\sim$ elevation** & island & 0.001 & 96.1 & $97.6^{\text {not sig. }}$ & $97.4^{\text {not sig. }}$ & $96.5^{\text {not sig. }}$ & $96.4^{\text {not sig. }}$ & $96.7^{\text {not sig. }}$ & $99.4^{\text {not sig. }}$ \\
\hline pSIE1 & $\sim$ species richness** & island & 0.002 & 96.5 & $98.5^{\text {not sig. }}$ & $95.1^{\text {not sig. }}$ & $98.2^{\text {not sig. }}$ & $96.5^{\text {not sig. }}$ & $96.9^{\text {not sig. }}$ & $96.1^{\text {not sig. }}$ \\
\hline pSIE 1 & $\sim$ species richness ${ }^{* * *}$ & habitat & $<0.001$ & 93.3 & $81.0^{* * *}$ & $95.2^{\text {not sig. }}$ & $78.0^{* * *}$ & $95.2^{\text {not sig }}$ & $95.1^{\text {not sig. }}$ & $95.2^{\text {not sig. }}$ \\
\hline pSIE 1 & $\sim$ time* $^{*}$ & habitat & 0.017 & 160.8 & not tested & not tested & not tested & not tested & not tested & not tested \\
\hline pSIE 1 & $\sim$ time $^{* * *}+$ time $^{2 * * *}$ & habitat & $<0.001$ & 95.4 & $96.1^{\text {not sig. }}$ & $84.3^{* * *}$ & $96.7^{\text {not sig. }}$ & $86.6^{* * *}$ & $83.3^{* * *}$ & $89.1^{* *}$ \\
\hline pMIE 1 & $\sim$ time $^{* *}$ & habitat & 0.006 & 41.0 & not tested & not tested & not tested & not tested & not tested & not tested \\
\hline pMIE1 & $\sim$ time not sig. + time $^{2 * *}$ & habitat & $<0.001$ & 35.2 & $30.3^{* *}$ & $30.5^{* *}$ & $32.4^{*}$ & $28.1^{* *}$ & $28.3^{* *}$ & $29.5^{* *}$ \\
\hline
\end{tabular}

process does also occur. As distances between the same habitats on different islands are similar, elevation could produce a target area effect for inter-island exchange, with smaller areas in the top regions. Larger areas would thus increase immigration rate and reduce speciation rate through genetic mixing and occupation of niche space. However, area is in general thought to increase speciation rates (Losos and Schluter 2000, Kisel and Barraclough 2010), which is also supported by the detected significant positive influence of habitat area on pSIE. It has been shown that for habitat specialists the relation between diversification and age may even be the opposite of the general trend if the associated habitat area varies different then the overall island area (Borges and Hortal 2009). In addition, the hypothesised 'elevation-driven isolation' is a process that is not only affecting single islands but also the archipelago as a whole. Some of the present summit scrub vegetation has probably migrated from Lanzarote and Fuerteventura to Tenerife and La Palma. Nonetheless, the summit scrub vegetation on all these islands is relatively isolated in respect to continental habitats of similar environmental conditions and the colonisation of new species is thus less likely than on less elevated ecosystems. The high elevation ecosystems remain poorer in species and leave ecological space for speciation. Even if this process might not apply to all species or is altered by several environmental influences, the geographic distance to (now or in the past) habitats with similar ecology on the nearby continent or adjacent archipelagos will influence the immigration and speciation processes.

A significant decrease of pSIE with species richness when comparing habitats on islands (with island as a random effect) would be expected from an increase of pSIE with elevation and a concordant decrease in species richness in smaller high elevation ecosystems. As a consequence for the island scale (i.e. comparing entire island data sets), this can lead to a fortuitous positive correlation of the two variables as larger islands tend to have more species (in general) and a higher pSIE due to high elevation ecosystems. Surprisingly, a pattern of a positive relationship between species richness and pSIE (as an indicator for diversification) was identified when comparing the same ecosystems on different islands (with habitat as a random effect). This analysis excludes elevation. A positive correlation between species richness and habitat area might be a possible cause.

We also confirm for the ecosystem scale that the relationship between pSIE and island age is hump-shaped, as predicted by the general dynamic theory of oceanic island biogeography (Whittaker et al. 2008). This rejects the influence of island elevation as a possible covariable for island age (Steinbauer and Beierkuhlein 2010). Given the typical ontogenesis of oceanic islands (Whittaker et al. 2007), we would expect island age and elevation to be inversely related. An ageing island is likely to become flatter. In addition, both elevation and age are said to influence island complexity (as a surrogate for carrying capacity) (Whittaker et al. 2007, 2008). It has been shown that working on the ecosystem scale can be a successful way of differentiating both variables. Testing possible implications of the general dynamic theory of oceanic island biogeography for ecosystems placed at similar altitudes on the same or different archipelagos bears promising future research opportunities.

Whittaker et al. (2008) and Triantis et al. (2008) suggest an important influence of area: on average the area threshold for SIEs is larger than that for MIE and non-endemic species. That is to say that MIEs and non-endemic species are more likely to persist even as fairly small populations due to an occasional influx of individuals from other islands, that has been referred to in the past as the rescue effect (Brown and Kodric-Brown 1977). Price (2004) showed for the Hawaiian Islands that the influence of area in defining diversity patterns is strong, also for pSIE and habitat types. One would assume that the smaller area of the subalpine scrub ecosystem probably also influences the presence of species groups, especially native non-endemics and MIE, reflected by the decline in the number of MIE as well as non-endemic species with altitude. Habitat area has a stronger effect on pSIE with habitat as random effect than with island as random effect. The main reason for this is probably that habitat area is strongly linked to island area and thus variation within one island is lower than between the islands. With habitat as random effect, habitat area follows a linear relation with island age that becomes hump shaped if the coastal shrub is included in the analysis (Fig. 2e). It seems that speciation tends to increase with habitat area, but this relation is altered in the lowland ecosystems that especially increase in area in old stages of an island. Area has also been cited as a main 
(a)

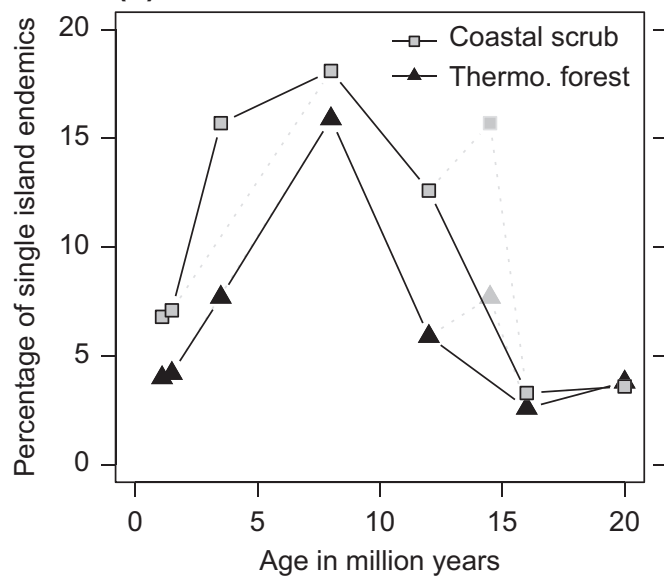

(b)

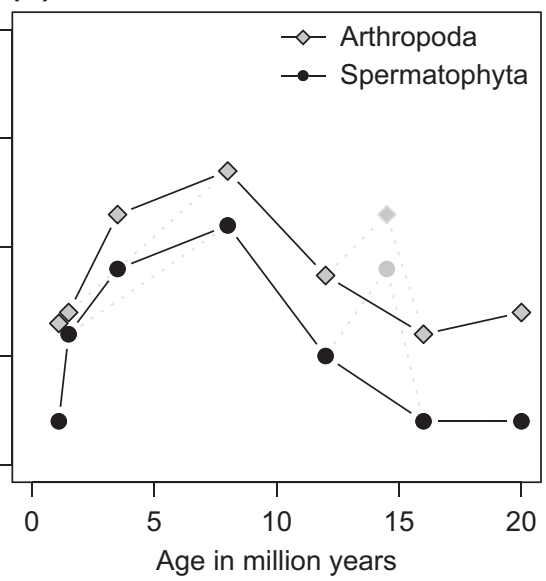

Figure 3. (a) For the ecosystem scale the relation of pSIE with island age resembles a hump shaped curve as suggested by the island immaturity speciation pulse model' in Whittaker et al. (2007). (b) On an inter-island scale the curve for pSIE and age used by Whittaker et al. (2007) is flatter. If an age of 14.4 million yr is assumed for Gran Canaria as suggested by Anderson et al. (2009) instead of 3.5 million yr as assumed by various authors following Whittaker et al. (2007), the curves would change as indicated by the grey dotted lines.

factor triggering speciation and the relation is suggested to be not linear with threshold area values for accelerating speciation rates (Losos and Schluter 2000). Thus, it is likely that a particular habitat type on an island needs to reach a certain size for triggering speciation. A further increase of habitat area will then lead to increasing speciation rates. An alternative explanation for an area threshold is an increased extinction rate. If an area is too small, only few lineages will survive for long enough to be recognised as species (Rosindell and Phillimore 2011). In many cases habitat area will be correlated with age in the beginning of island evolution, which makes a differentiation of both variables difficult. On old islands habitat size seems to be of less importance for speciation, probably because the availability of empty niche space is reduced due to species pool saturation and decreasing altitude and topographical complexity.

The habitat types used here vary in age. Several of them are younger than the old islands (thermophilous woodlands, coastal scrub, summit scrub). The pine forest and laurel forest can be considered old ecosystems since fossils for Pinus canariensis are dated 13 Myr on Gran Canaria (García-Talavera et al. 1995, Domínguez et al. 2010). The low elevation ecosystems seem to be younger or their species composition has entirely changed. However, there are several reasons why we decided to focus on island age. Fist, the species (or their ancestors) living in a specific habitat might be older than the habitat type. Second, in the Whittaker et al. (2008) model (that is our reference in this aspect) age is the time that was available for species to colonisation or speciation. This time is constrained either by the islands age or any sterilising mega event. In case of habitat types this becomes very complicated, because climatic fluctuations might shift the spatial position of the climatic envelope of a current habitat type, however, the species in this habitat might be different in their climatic sensitivity leading to a mixture or rearrangement of species communities with time. Third, island age is not only the time available for speciation, but also a surrogate for some other characteristics (like e.g. complexity). The fact that we found a relation on the habitat level with island age is a strong indica- tor that the role of age in the model is currently not understood but probably crucial for a further progress in island biogeographical theory.

Triantis et al. (2008) highlight cases that might flaw SIE as an indicator for in situ speciation. There are three points where endemism might not only evolve from intrinsic factors of the island, but also from extrinsic ones. Firstly, SIE might have evolved but already gone extinct. However, if the extinction of previously evolved SIE is as probable as the extinction of previously immigrated species, these cases will not influence the distribution pattern of pSIE. However, SIE might be more likely to survive, as in order to speciate a population has to persist for a long time and, presumably, be relatively abundant. If this hypothesis is valid it is probably equally applicable to all islands and habitats. Secondly, SIE can lose their status and turn into 'only' MIE by colonising a second island within the archipelago. However, the consistent distribution pattern for pMIE and pSIE and the fact that archipelago endemism is also linked to speciation supports the connection of diversification to pMIE, pSIE and elevation. MIE on the other hand can also become 'false SIEs' - a case that was not mentioned by Triantis et al. (2008). This could take place in particular as a result of human extinction pressure leading to the disappearance of MIEs on all islands except one. Finally, Triantis et al. (2008) mentions that ancient immigrants might have become extinct in the region of their origin (palaeoendemism). This point is particularly valid for the Canary Islands, where a lot of species in the main source region (mainland Africa) might have gone extinct due to climatic changes (Axelrod 1975, Le Houerou 1997). However, these species should mainly be distributed in the low to mid elevation ecosystems, due to the corresponding elevation of the source region, and are therefore more likely to be MIE than SIE, as successfully immigrating species should be able to colonise more than one island.

An extinction of species on mainland Africa could be a possible explanation for the relatively high values for pSIE and pMIE within thermophilous woodland. Some 
of the species found at low and mid altitudes might be remnants of species that survived the climatic ice age fluctuations only on the Canary Islands, while becoming extinct on the African mainland. Lowland ecosystems might have survived glaciations due to an upward shift, which was not possible for high elevation ecosystems. However, laurel and pine forests are supposed to be older than other Canarian ecosystems. This is especially true for the thermophilous woodlands that are comparable to Mediterranean sclerophyll forests (Fernández-Palacios et al. 2009). It is suggested that these ecosystems substituted the former palaeotropical flora of southern Europe and North Africa in the late Miocene and Pleistocene periods (Axelrod 1975, Barrón and Pierrot 2006). The thermophilous woodland constitutes the zonal ecosystem that was most disturbed by anthropogenic activities both in the prehistoric (i.e. through fire, introduced goats and pigs) and historic periods (i.e. with settlements and agriculture) (Fernández-Palacios et al. 2009). One could argue that land use practises together with the resulting smallscale disturbance regime might have formed a heterogeneous landscape where in situ diversification was not only triggered by environmental complexity but also by extinction pressure. However, an explanation for the high values of pSIE based on human influence is very unlikely as the Canary Islands were only colonised by man $2500 \mathrm{yr}$ ago (de Nascimento et al. 2009) and practically all SIE in this habitat are shrub species.

\section{Conclusions}

Our results add valuable insights for an improved understanding of island archipelago systems. We were able to show that pSIE (and thus diversification) is linked to the elevation of an ecosystem. This is probably caused by an increasing spatial isolation of elevated ecosystems on an island. It may serve as an additional explanation for a hypothetical fortuitous correlation between pSIE and the species number on an island scale (Emerson and Kolm 2005a, b). However, we identified the same correlation on the ecosystem scale, possibly caused by a correlation between species richness and habitat area.

The general dynamic theory of oceanic island biogeography (Whittaker et al. 2007, 2008) postulates a certain correlation between island elevation and complexity (indicator for vacant ecological niches) triggered by island age. But as pSIE even within the same ecosystems on different islands follows a hump-shaped relationship with island age (Fig. 2a), the importance of island age (or the time available for diversification) is stressed as an independent factor. Diversification is also related to habitat area, a factor that seems to be of special importance on young islands.

These insights support the results of current island biogeographical theories for different spatial scales, opening up new opportunities for future scientific focus and discussion. Further application of island-specific theory at the habitat level will not only result in a promising new insight but will also be much easier to perform (in case that habitat types can be defined) than studies on the island scale.
Acknowledgements - We would like to thank Joaquín Hortal, Christoph Kueffer, Albert Phillimore, Björn Reineking and the anonymous reviewers for very valuable comments and advice.

\section{References}

Alexander, J. M. et al. 2011. Assembly of nonnative floras along elevational gradients explained by directional ecological filtering. - Proc. Natl Acad. Sci. USA 108: 656-661.

Anderson, C. L. et al. 2009. Life, death and fossilization on Gran Canaria - implications for Macaronesian biogeography and molecular dating. - J. Biogeogr. 36: 2189-2201.

Anguita, F. et al. 2002. Los Volcanes de Canarias. Guía Geológica e Itinerarios. - Ed. Rueda, Madrid.

Axelrod, D. I. 1975. Evolution and biogeography of Madrean - Tethyan sclerophyll vegetation. - Ann. Mo. Bot. Gard. 62: 280-334.

Barrón, E. and Pierrot, D. 2006. La vegetación forestal en el Terciario. - In: Carrión, J. et al. (eds), Paleoambientes y cambio climático. Fundación Séneca/Agencia de Ciencia y Tecnología de la Región de Murcia, Murcia, pp. 55-76.

Bates, D. and Maechler, M. 2009. lme4: linear mixed-effects models using S4 classes. - R package ver. 0.999375-32.

Birand, A. and Howard, D. J. 2008. The relationship between proportion of endemics and species diversity on islands: expectations from a null model. - Ecography 31: 286-288.

Borges, P. A. V. and Hortal, J. 2009. Time, area and isolation: factors driving arthropod speciation at the Azorean Archipelago. - J. Biogeogr. 36: 178-191.

Brown, J. H. and Kodric-Brown, A. 1977. Turnover rates in insular biogeography - effects of immigration on extinction. - Ecology 58: 445-449.

Bunnefeld, N. and Phillimore, A. B. 2011. Island, archipelago and taxon effects: mixed models as a means of dealing with the imperfect design of nature's experiments. - Ecography 34.

Cadena, C. D. et al. 2005. Is speciation driven by species diversity? - Nature 438: E1-E2.

de Nascimento, L. et al. 2009. The long term ecology of the lostforests of La Laguna. - J. Biogeogr. 36: 499-514.

del Arco Aguilar, M. J. 2006. Mapa de Vegetación de Canarias. - Grafcan, Santa Cruz de Tenerife.

Domínguez, F. et al. 2010. Using taxonomic and phylogenetic evenness to compare diversification in two Island Floras. - Perspect. Plant Ecol. Evol. Syst. 12: 93-106.

Emerson, B. C. and Kolm, N. 2005a. Species diversity can drive speciation. - Nature 434: 1015-1017.

Emerson, B. C. and Kolm, N. 2005b. Is speciation driven by species diversity? - Reply. - Nature 438: E2.

Emerson, B. C. and Kolm, N. 2007. Response to comments on 'Species diversity can drive speciation'. - Ecography 30: 334-338.

Fernández-Palacios, J. M. et al. 2009. Los bosques termófilos de Canarias. - Cabildo Insular de Tenerife, Santa Cruz de Tenerife.

Fernández-Palacios, J. M. et al. 2011. A reconstruction of PalaeoMacaronesia, with particular reference to the long-term biogeography of the Atlantic island laurel forests. - J. Biogeogr. 38: 226-246.

García-Talavera, F. 1999. La Macaronesia. Consideraciones geológicas, biogeográficas, y paleoecológicas. - In: FernándezPalacios, J. M. et al. (eds), Ecología y cultura en Canarias. Cabildo Insular de Tenerife, pp. 39-63.

García-Talavera, F. et al. 1995. Vegetales fósiles en el complejo traquítico-sienítico de Gran Canaria. - Rev. Acad. Canaria Cienc. 7: 77-91.

Gruner, D. S. et al. 2008. Does species richness drive speciation? A reassessment with the Hawaiian biota. - Ecography 31: 279-285.

Heaney, L. R. 2000. Dynamic disequilibrium: a long-term, largescale perspective on the equilibrium model of island biogeography. - Global Ecol. Biogeogr. 9: 59-74. 
Izquierdo, I. et al. (eds) 2004. Lista de especies silvestres de canarias - hongos, plantas y animales terrestres, 2nd ed. - Consejería de Política Territorial y Medio Ambiente Gobierno de Canarias, La Laguna, Tenerife.

Kiflawi, M. et al. 2007. Species diversity can drive speciation: comment. - Ecology 88: 2132-2135.

Kisel, Y. and Barraclough, T. G. 2010. Speciation has a spatial scale that depends on levels of gene flow. - Am. Nat. 175: 316-334.

Le Houerou, H. N. 1997. Climate, flora and fauna changes in the Sahara over the past 500 million years. - J. Arid Environ. 37: 619-647.

Lomolino, M. 1990. The target area hypothesis: the influence of island area on immigration rates of non-volant mammals. - Oikos 57: 297-300.

Lomolino, M. V. 2000. A call for a new paradigm of island biogeography. - Global Ecol. Biogeogr. 9: 1-6.

Losos, J. B. and Schluter, D. 2000. Analysis of an evolutionary species-area relationship. - Nature 408: 847-850.

MacArthur, R. H. and Wilson, E. O. 1967. The theory of island biogeography. - Princeton Univ. Press.

Marrero, A. and Francisco-Ortega, J. 2001. Evolución en islas: la metáfora espacio-tiempo-forma, 2nd ed. - In: FernándezPalacios, J. M. and Martín, J. L. (eds), Naturaleza de las Islas Canarias. Ecología y Conservación. Turquesa, pp. 133-140.

Marshall, H. D. and Baker, A. J. 1999. Colonization history of Atlantic island common chaffinches (Fringilla coelebs) revealed by mitochondrial DNA. - Mol. Phylogenet. Evol. 11: 201-212.

Pereira, H. M. et al. 2007. Does species diversity really drive speciation? - Ecography 30: 328-330.
Price, J. P. 2004. Floristic biogeography of the Hawaiian Islands: influences of area, environment and paleogeography. - J. Biogeogr. 31: 487-500.

Rosindell, J. and Phillimore, A. B. 2011. A unified model of island biogeography sheds light on the zone of radiation. - Ecol. Lett. 14: 552-560.

Stanley, S. 1999. Earth system history. - Freeman.

Steinbauer, M. J. and Beierkuhnlein, C. 2010. Characteristic pattern of species diversity on the Canary Islands. - Erdkunde 64: $57-71$.

Triantis, K. A. et al. 2008. Evolutionary species-area curves as revealed by single-island endemics: insights for the interprovincial species-area relationship. - Ecography 31: 401-407.

Vilenkin, B. Y. et al. 2009. A random process may control the number of endemic species. - Biologia 64: 107-112.

Whittaker, R. J. et al. 2007. The island immaturity - speciation pulse model of island evolution: an alternative to the 'diversity begets diversity' model. - Ecography 30: 321-327.

Whittaker, R. J. et al. 2008. A general dynamic theory of oceanic island biogeography. - J. Biogeogr. 35: 977-994.

Whittaker, R.J. et al. 2010. A general dynamic theory of oceanic island biogeography: extending the MacArthur-Wilson theory to accommodate the rise and fall of volcanic islands. - In: Losos, J. B. and Ricklefs, R. E. (eds), The theory of island biogeography revisited. Princeton Univ. Press, pp. 88-115.

Witt, C. C. and Maliakal-Witt, S. 2007. Why are diversity and endemism linked on islands? - Ecography 30: 331-333.

Zobel, M. et al. 2011. The formation of species pools: historical habitat abundance affects current diversity. - Global Ecol. Biogeogr. 20: 251-259. 